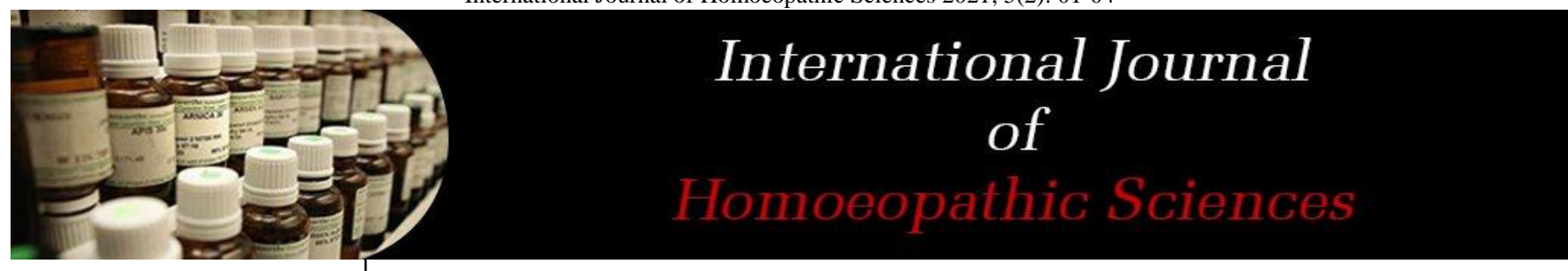

E-ISSN: $2616-4493$ P-ISSN: 2616-4485 www.homoeopathicjournal.com IJHS 2021; 5(2): 01-04 Received: $02-12-2020$ Accepted: 05-01-2021

Dr. Bikash Biswas BHMS, MD (2 nd year), Mahesh Bhattacharyya Homoeopathic Medical College and Hospital, West Bengal, India

Dr. Sanjukta Mandal BHMS, MD, 3 rd Year, Mahesh Bhattacharyya Homoeopathic Medical College and Hospital, West Bengal, India
Corresponding Author: Dr. Bikash Biswas BHMS, MD (2 nd year), Mahesh Bhattacharyya Homoeopathic Medical College and Hospital, West Bengal, India

\section{Role of homoeopathy in epidemic disease}

\section{Dr. Bikash Biswas and Dr. Sanjukta Mandal}

DOI: $\underline{\text { https://doi.org/10.33545/26164485.2021.v5.i2a.352 }}$

\section{Abstract}

Hahnemann constantly worked on this type of condition in his era. In epidemic diseases there was always a strong proof that homoeopathic medicine can be the only way out that scenario. In recent times pandemic (COVID-19) situation all over the world, homoeopathic medicines prescribed the on basis of similia, patients cen be recovered.

Keywords: Homoeopathy, Epidemic disease. Abbreviations: ILI- Influenza like illness

\section{Introduction}

Epidemic disease

Epi= upon; demon= people.

The unusual occurrence in a community of region of disease, specific health related behavior, outbreak in large no ${ }^{[1]}$.

Outbreak: an outbreak is a sudden increase in occurrence of an infectious disease in a particular time and place ${ }^{[1]}$. Hahnemannian concept of epidemic disease It attacks several persons, with similar sufferings from same cause ${ }^{[2]}$. Generally becomes infectious when prevail among thickly ongregated mass of human beings ${ }^{[2]}$. Calamities of war, inundations and famine are causes of epidemic disease ${ }^{[2]}$

\section{Epidemic disease}

An epidemic usually affecting a large proportion of the population occurring over a wide geographic area such as section of nation, entire nation, a continent or the world ${ }^{[3]}$. Covid 19, 2019-2020 to be continued.

\section{Types}

Common source epidemics point source epidemics ${ }^{[3]}$ multiple source epidemics ${ }^{[3]}$ slow epidemics [3]. Propagated epidemics ${ }^{[3]}$ Person to person ${ }^{[3]}$ Anrthropod epidemics ${ }^{[3]}$ Animal reservoir ${ }^{[3]}$ covid $-19: 2019-2020$ to be continued.

\section{Current burden of health}

1. Corona virus ${ }^{[4]}$

2. Corona means crown ${ }^{[5]}$

3. Covered with spiky proteins ${ }^{[5]}$

4. RNA virus ${ }^{[6]}$

5. Zoonotic virus ${ }^{[6]}$

\section{Incubation Period}

The incubation period: 2-14 days after exposure ${ }^{[7]}$

Transmission of corona virus, covid $-19^{[8]}$ person to person ${ }^{[8]}$. Highly contagious ${ }^{[8]}$ from droplets ${ }^{[8]}$ From touch of the objects which are touched by infected persons, touching mouth, nose, eyes ${ }^{[8]}$ Asymptomatic person can transmit without showing any symptoms ${ }^{[8]}$.

\section{Homoeopathic point of view in}

Epidemic disease

\section{Introduction}

In conventional system to prevent the burden of the epidemic diseases vaccination was the only way out. But Homoeopathic remedy will allow the vital force immediately to deal with any acute exposure or attack of epidemic diseases. 


\section{History of treatment of Epidemic diseases in Homoeopathy Sammuel Hahnemann \\ History of smooth scarlatina epidemics \\ In 1801, smooth scarlatina of Sydenham [9] attacked epidemically all children, who escaped in former epidemic. In epidemic in Konigslutter, all children who took belladonna in a very small dose remained unaffected by it as it protects from epidemic attack ${ }^{[10]}$}

\section{Scarlet fever of sydenham}

In year 1801 a kind of purpura miliaris (roodvonk), which came from west, was by physician onfounded with scarlet fever, notwithstanding that they exhibit totally different symptoms, that the atter found its prophylactic and curative remedy in belladonna, the former in aconite ${ }^{[11]}$.

\section{Hahnemannian concept of collective \\ Disease}

First case of epidemic may not give the complete picture ${ }^{[12]}$ Close observation of several cases the physician obtains the totality of symptoms of the epidemic [12] 'several cases of every such collective disease that he can become conversant with the totality of its signs \&amp; symptoms' ${ }^{\text {[12] }}$.

\section{Hahnemanian concept of uncured epidemic Intermittent fever}

Develops psora internally by maltreatment ${ }^{[13]}$ Will be cured by minute \&amp; rarely repeated dose of sulphur or heper sulph in high potency ${ }^{[13]}$.

\section{Hahnemannian concept of epidemic fever}

Epidemic fever where none are endemic [14] Nature of chronic disease [14] Single acute paroxysm [14] Uniform, peculiar character common to all ${ }^{[14]}$. This character guides for the discovery of homoeopathic remedy suitable for all cases ${ }^{[14]}$.

\section{Hahnemannian concept in prevention of measles}

It seems to me somewhat probable that a similar employment of belladonna would also preserve from measles ${ }^{[15]}$.

\section{Hahnemannian concept on the prevailing fever}

'on the other hand there is a mineral, which is extraordinary action on human body, is capable of exciting those symptoms which make up our fever in most perfect \&amp; complete manner' ${ }^{[16]}$. Arsenicum album it can cure the greatest and worst portion of our fevers quickly, easily, and with the greatest certainty ${ }^{[16]}$ (prevailed for a year past in Germany) ${ }^{[16]}$.

\section{Hahnemannian concept:}

Prevention in epidemic disease (lesser writings 171 page no, friends of health)

Should avoid over eating ${ }^{[17]}$ Night watching should be avoided ${ }^{[17]}$ Over fatigue of the body and mind should be avoided ${ }^{[17]}$ Never visit a patient in empty stomach [17] 'in such cases, I have taken a drachm of cinchona bark in wine every three quarters of an hour, until all danger of infection was completely over' ${ }^{[17]}$.

\section{Concept of other stalwarts}

J. T. Kent

Kentian

\section{Concept}

'The original simple psora has added to sycosis \&amp; syphilis, have now effected a state, they have continued to effect state in mankind, whereby the entire race is so susceptible to acute affections that many of our citizens have every little thing that comes along, and every little epidemic of influenza brings them down with an acute attack' ${ }^{[18]}$ which can only be treated by symptom similarity with proper anamnesis and proper similimum ${ }^{[18]}$. According to Kent there is only one way to cure, that is symptomssimilarity. He also said day by day medicine could be changed according to patient's individualization ${ }^{[19]}$. You will perhaps find that half a dozen remedies indicated in large no of cases. The one remedy seems to best efficacious to the general nature of the sickness, you will find the prophylaxis ${ }^{[19]}$.

\section{John henry clarke homoeopathic prevention clarke}

Dr. Clarke: in case of influenza like illness, DR CLARKE has given in fluenzinum ${ }^{[20]}$. "The general directions, I give to my patients when cold appear in a family let all those who are unaffected take arsenicum album 3 thrice daily, and let the patient take in fluenzinum 30 every hour or two [20] This generally prevents the spread of the cold and clears up the case. whether they are of the influenza type or not ${ }^{[20]}$.

\section{Clarke: on in fluenzium}

Influenza has the property of developing old troubles, \& amp; thus it takes an infinite variety of forms in different persons, so that in fluenzinum need not be expected to cure all cases unaided, or indeed, to be appropriate to every case [20].

\section{Pierre Schmidt}

\section{Pierre Schmidt on Oscillococcinum}

Influenza at the beginning as a preventive, as well as during convalescence ${ }^{[21]}$ Influenzas of all types, especially in early stages ${ }^{[21]}$ Epidemic influenza ${ }^{[21]}$ Tendency to get influenza [21] Oscillococcinum 200c every 3 hours or repeat if necessary ${ }^{[21]}$.

\section{Josepeh Roy concept, on Oscillococcinum}

He observed 1925 in some culture condition (the existence of germ animated by oscillating movement) [22] Oscillococcinum as a preventive in flu like illness (influenza) ${ }^{[22]}$ Oscillococcinum was developed by Boiron lab in France ${ }^{[22]}$.

\section{Effects of homoeopathy in outbreak of disease Published in various Journals: William f.baker (Philadelphia)}

Following Dr. ohen's method gelsemium: ' has its control of the infection and immunity produced by gelsemium in the rabit blood' [23] 'Experiment shows that gels value in all infections. Including central nervous system' ${ }^{\text {[23]. }}$.

Bryonia: 'acts on the peripheral sensory functions and marked gastro enteric system. The deep action on lung is more of the nature of hypostasis from collapse' ${ }^{[23]}$.

JN Majumder, PC Majumder, Nilambar Hui 1919 (The Calcutta Homoeopathic Medical College And Hospital). Epidemic of influenza fever in Calcutta in august 1918 where the heart seems to be affected remedies were ${ }^{[24]}$. Arsenic [24] 
Carbo veg [24]

Lobelia ${ }^{[24]}$

Calcarea ars ${ }^{[24]}$

Eupatorium per ${ }^{[24]}$

J.N. Majumder cured 300 patients with these remedies within 7 days ${ }^{[24]}$

\author{
Hahnemannian monthly conducted by dr. Donald \\ Macfurlon, Philadelphia: NOV 1918: \\ Remedies for influenza ${ }^{[25]}$ \\ Arsenic album ${ }^{[25]}$ \\ Bryonia Alba ${ }^{[25]}$ \\ Gelsemium [25] \\ Phosphorous [25] \\ Ipecacuanha ${ }^{[25]}$ \\ Antim tart ${ }^{[25]}$ \\ Euphatorium perfolatum ${ }^{[25]}$
}

With their respective generalities and peculiar characteristics.

M. Johnson (Chicago)

According to law of similaris, the principle remedies are ${ }^{[26]}$ Arsenic album ${ }^{[26]}$

Antim tart ${ }^{[26]}$

\section{Recent study: Homoeopathic}

\section{Approach. In West Bengal}

All homoeopathic medical colleges provided arsenicum album 30 as prophylaxis in respective areas and studies state that all non-immune cases had not suffered with fever or any kind of ILI symptoms ${ }^{[28]}$. In Naiminath homoeopathic medical college and hospital they are treating 50 positive cases with homoeopathic medicine, all patient now negative in lab test ${ }^{[28]}$.

\section{Kent repertory}

In kent repertory there is only one rubric naming under 'extremities' pain' influenza during'- Bryonia alba [26] Gelsemum ${ }^{[26]}$ BRYONIA (1st grade) ${ }^{[29]}$. Natrum sulph ${ }^{[26]}$ EUP-PER ( $1^{\text {st }}$ grade) ${ }^{[29]}$ nd with their respective generalities and peculiar characteristics. We have given these remedies in potencies from the 6 th to 2000 th, with the result that every case has recovered in few days ${ }^{[26]}$.

American institute of homoeopathy and canadian academy of homoeopathy, may 2 nd 2020: by andre saine (On Covid management by homoeopathy):

A series of six cases of covid from istanbul ${ }^{[27]}$ Symptoms common to all patients,in early stage ${ }^{[27]}$ And progressing into pneumonia ${ }^{[27]}$ These severe covid patients treared with homoeopathy [27] Symptomatology from pathology reports,autopsies \&amp; post intubation outcome [27]. Viewed from repertorial analysis ${ }^{[27]}$ Bryo, sulph, phos, ars alb, carbonium oxigenisatum ${ }^{[27]}$ Most commonly indicated remedy carbonium oxygenisatum, as prophylaxsis \&amp; curative ${ }^{[27]}$ Aconite, causticum, chel, euph, gels (2 grade) ${ }^{[29]}$ Naja (3 rd grade) ${ }^{[29]}$.

The symptoms into rubrics, kent's repertory (Early stages) Nose' coryza' fever with':bryo, merc, gels, aco ${ }^{[30]}$ Nose' coryza' fever with' summer': gels ${ }^{[30]}$ Nose' coryza' sore throat with': merc, nit- ac, nux -vom, phos ${ }^{[30]}$ Fever' chill: acon, bell,ars, cham, rhus tox ${ }^{[31]}$ Fever' external heat':acon, ars, bell, bry, cham ${ }^{[31]}$ Cough'dry':acon, ars, bell, bry, puls, rumex ${ }^{[32]}$ Throat' pain' sore: ars, bapt, bell, calc ${ }^{[33]}$ Pulse full: aco, bell, bryo, ars, gels, hyos, stram ${ }^{[34]}$.

\section{Conclusion}

Homoeopathy can be utilized effectively in outbreak of any infectious disease. The effectiveness of homoeopathic preventive medicines needs further clinical, molecular studies as well. In any kind of epidemic disease like influenza, any kind of exhausting fever homoeopathic medicine works miraculously.

\section{References}

1. Park K, park's textnook of preventive and social medicine, 23 rd edition.

2. Hahnemann S, Organon of Medicine, Translated By R E Dudgeon, Modern Homoeopathic Publication 5th edition.

3. Park K, park's textnook of preventive and social medicine, 23 rd edition.

4. http://en.m.wikipedia.org/wiki/coronavirus.

5. Almeiia JD, Berry DM, Cunningham $\mathrm{CH}$, Hamre D, Hofstad MS, Mallucci L. Virology: coronavirus 1968.

6. Woo pc, Huang y, Lau sk, Yuen KY (August 2010). "coronavirus geonomics and bioinformatics analysis". Viruses.

7. http://en.m.wikipedia.org/wiki/coronavirus.

8. Wilkinson L, Baldwin Willian. Oxford handbook of clinical medicine, 9 th south Asia edition.

9. Hahnemann S. Organon Of Medicine, aphorism33, Translated By R E Dudgeon, Modern Homoeopathic Publication 5th edition.

10. Hahnemann S, lesser writings, cure and prevention of scarlet fever.

11. Hahnemann S. Organon Of Medicine, aphorism73, footnote 2, Translated By R E Dudgeon, Modern Homoeopathic Publication $5^{\text {th }}$ edition. Hahnemann S, Organon of Medicine, aphorism Translated By R E Dudgeon, Modern Homoeopathic Publication 5th edition.

12. Hahnemann S. Organon of Medicine, aphorism 242, Translated By RE Dudgeon, Modern Homoeopathic Publication 5th edition.

13. Hahnemann S. Organon of Medicine, aphorism 241, Translated By R E Dudgeon, Modern Homoeopathic Publication 5th edition.

14. Hahnemann S. lesser writings, protection against scarlet fever, page no 381.

15. Hahnemann S. lesser writings, protection against scarlet fever, page no 564.

16. Hahnemann S. lesser writings, protection against scarlet fever, page no 171.

17. Kent JT. Lectures on Homoeopathic Philosophy, B Jain Publishers, 2013; Lecture xix.

18. Kent JT. Lectures on Homoeopathic Philosophy, B Jain Publishers, 2013.

19. Clarke JH, Materia medica,

20. Murphy J, Lotus Materia medica,

21. Murphy J, Lotus Materia medica,

22. Baker WF, (Philadelphia) research work in influenza (blood immunity): Jan, 1920,the American institute of homoeopathy.

23. Majumder JN. Majumder PC, Hui, n, The Indian homoeopathic review: (February 1919) (the Calcutta 
homoeopathic medical college and hospital).

24. MacFarlane D, Hahnemannian monthly, Philadelphia: November 1918:

25. Johnson $\mathrm{M}$, The north American journal of homoeopathy, Virginia (Chicago)

26. Saine A, American institute of homoeopathy and Canadian academy of homoeopathy, may 2 nd 2020, (on covid management by homoeopathy)

27. Data, GOVT, West Bengal, all govt homoeopathic medical colleges. 2019-2020.

28. Kent JT, repertory of homoeopathic Materia medica, chapter- extremities, pain, 9 th impression, 2015, 1045.

29. Kent JT, repertory of homoeopathic Materia medica, chapter-nose, 9 th impression, 2015.

30. Kent JT, repertory of homoeopathic Materia medica, chapter-nose, 9 th impression, 2015.

31. Kent JT, repertory of homoeopathic Materia medica, chater-cough, 9 th impression, 2015.

32. Kent JT, repertory of homoeopathic Materia medica, chapter-throat, 9 th impression, 2015.

33. Kent JT, repertory of homoeopathic Materia medica, chapter- generalities, 9 th impression, 2015 